\title{
Efficacy of New Insecticide Molecules against Major Predatory Insects in Kusmi Lac
}

\author{
Savita Aditya and S.P. Singh* \\ Krishi Vigyan Kendra, Raigarh-496001, India \\ Indira Gandhi Krishi Viswavidyalaya, Raipur (C.G.), India \\ *Corresponding author
}

\section{A B S T R A C T}

\begin{tabular}{|l|}
\hline K e y w o r d s \\
$\begin{array}{l}\text { Kusmi lac, Kerria lacca, } \\
\text { Natural enemies of lac } \\
\text { crop, New insecticide } \\
\text { molecule }\end{array}$ \\
\hline Article Info \\
\hline $\begin{array}{l}\text { Accepted: } \\
\text { 04 November } 2018 \\
\text { Available Online: } \\
\text { 10 December } 2018\end{array}$ \\
\hline
\end{tabular}

The study was carried out for the assessment of abundance of predatory insects associated with lac insect Kerria lacca (Kerr) and their management through new insecticide molecule in kusmi lac during July-October 2015-16 and 2016-17. A combination of Emamectin benzoatate $5 \% \mathrm{SG}+$ Carbendazim $50 \mathrm{WP}\left(\mathrm{T}_{1}\right)$, Indoxacarb $14.5 \% \mathrm{SC}+$ Carbendazim 50 WP $\left(\mathrm{T}_{2}\right)$ and Control $\left(\mathrm{T}_{3}\right)$ was evaluated against the predators of the lac insect. Pesticides application significantly reduced the incidence of major predators Eublemma amabilis Moore and Pseudohypatopa pulverea Mayr in comparison to $\left(\mathrm{T}_{3}\right)$. There was a reduction in the population of predatory insects 81.97 per cent in $T_{1}$ and 77.78 per cent $\mathrm{T}_{2}$ respectively over the year. It was seen that the different samples of lac collected from different lac growing areas of Chhattisgarh and noted that not a single sample was free from the attack of predator Eublemma amabilis Moore and Pseudohypatopa pulverea Mayr and appeared as major problem of lac host plants and losses consideration level in most of the areas.

\section{Introduction}

Lac is a natural, biodegradable, non-toxic, odour less, taste less, hard resin, non-injurious to health and non- timber forest produce (NTFP). Lac is one of the most valuable gifts of nature and only resin of animal origin secreted by a tiny scale insect, Kerria lacca (Kerr.) belonging to the family Lacciferidae (Kerriidae), superfamily Coccoidea and order Hemiptera (Pal, 2009 and Mohanta et al., 2012). Lac is an export oriented commodity, cultivated in the states of Jharkhand, Chhattisgarh, West Bengal, Madhya Pradesh, Odisha, Maharashtra, parts of Uttar Pradesh,
Andhra Pradesh, Gujarat and NEH region. Chattisgarh is today the major contributor of raw lac followed by Jharkhand. Lac cultivation is one of the important secondary sources of income for villagers and this is particularly more in the tribal districts. The important lac producing areas in the state are Kanker, Korba, Raigarh, Rajnandgaon and Bilaspur. On an average around 28 per cent of total agriculture income of the households is contributed by lac cultivation (Jaiswal et al., 2006), and more than 80 per cent of lac produced in India is exported (Pal et al., 2010; Ramani and Sharma, 2010). The lac insect is prone to attack by insect predators and 
parasitoids. Among them, two Lepidopteron predators, Eublemma amabilis Moore (Lepidoptera: Noctuidae) and Pseudohypatopa pulverea Mayr (Lepidoptera: Blastobasidae) are key pests causing a loss due to bore into the lac encrustation where they remain confined while they feed on the lac insects. In case of severe infestation, these predators have been reported to cause complete crop failure and are severe bottlenecks in introducing lac culture in new areas. Predators cause around 35 to 40 per cent loss to lac production, while 5 to 10 per cent damage by parasitoids (Jaiswal et al., 2008). Several management efforts to reduce the yield loss due to predators and parasitoids range from cultural and physical (Horn and Page, 2008; Bhattacharya et al., 2006), biological (Bhattacharya et al., 2008; SiMing et al., 2010), and chemical (Singh et al., 2009). Ever since the Government of India has banned endosulfan, there was a felt need to evaluate newer and safer insecticides for the management of predators and parasitoids of lac insect (Arora et al., 2009). Hence the present research entitled lac associated major predatory insects and their management through new insecticide molecule in kusmi lac of Chhattisgarh plains.

\section{Materials and Methods}

The study was carried out on kusmi lac for predatory insects associated with lac insect Kerria lacca (Kerr) and their management through new insecticide molecule during JulyOctober 2015-16 and 2016-17. The experimental site is located on the Northern part of Chhattisgarh and lies at $21^{\circ} 54^{\prime} \mathrm{N}$ latitude and $83^{\circ} 24^{\prime} \mathrm{E}$ longitude with an altitude of $215 \mathrm{~m}$ above the mean sea level (MSL). The field experiments was conducted on kusmi lac (Schleichera oleosa) crop with rocking Gator/Foot sprayer and will be targeted on lac bearing tender twigs to cover the lac encrustation with insecticidal spray. The experiment was laid out in randomized block design comprising three treatments i.e. $\mathrm{T}_{1}$ [Emamectin benzoatate $5 \%$ SG @ $0.5 \mathrm{ml}$ lit $^{-1}+$ Carbendazim 50 WP @ 3 gm sprayer ${ }^{-1}$ at 30 days and 60 days after BLI (Brood lac inoculation)], $\mathrm{T}_{2}$ [Indoxacarb14.5 \% $\mathrm{SC}$ @ $0.48 \mathrm{ml} \mathrm{lit}^{-1}+$ Carbendazim Carbendazim 50 WP @ 3 gm sprayer ${ }^{-1}$ at 30 days and 60 days after BLI] and $\mathrm{T}_{3}$ [Control (Lac growers practice i.e. no use of insecticide] with replicated three times and 10 nos. of women lac growers.

For quantification of predators in lac culture, both treated and untreated lac bearing sticks of $15 \mathrm{~cm}$ shoot length from each treatment will be collected 15 days after first and second spraying as well as the stage of crop maturity (brood harvesting) following the method of stratified destruction random sampling. The sample will be kept in 60 mesh nylon net bags to assess larvicidal action of the insecticides on lepidopteron predators (Eublema amabilis and Pseudohypatopa pulverea) of lac insect. The number of living and dead larva as well as adult moths emerged from the caged samples will be quantified in terms of predators per 15 $\mathrm{cm}$ lac encrustation and percentage reduction in the incidence of predators will be calculated subsequently.

Untreated value-Insecticide treatment value $\%$ Reduction of Predators = ------------- x 100

Untreated value

At harvest the yield was recorded $\mathrm{kg} /$ tree in each treatment. The comparative increase in lac yield and benefit cost ratio (increment lac yield and B:C ratio) was calculated by subtracting market value of lac yield in control taking into account the prevailing market price of product, input and labor charges.

Yield of protected treatment Yield of unprotect treatment

Avoidable loss $(\%)=$-------------------- x 100

Yield of protected treatment 


\section{Results and Discussion}

\section{Efficacy of new insecticide molecules}

The present study was conducted on $E$. amabilis Moore and Pseudohypatopa pulverea Mayr incidence was recorded from randomly selected $15 \mathrm{~cm}$ lac sticks of each treatment depicted in table 1 . The insecticidal treatments were applied two times, first at 30 days of brood lac inoculation (BLI) and second 60 days of brood lac inoculation (BLI). After first spray among the treatments on the basis of pooled mean data recorded on 30 DABLI indicate $\mathrm{T}_{1}$ [Emamectin benzoatate $5 \% \mathrm{SG} @$ $0.5 \mathrm{ml} \mathrm{lit}^{-1}+$ Carbendazim 50 WP @ 3 gm sprayer $\left.^{-1}\right]$ was recorded least infestation 1.90 insect / $15 \mathrm{~cm}$ lac stick and 1.5 insect / $15 \mathrm{~cm}$ lac stick recorded on $60 \mathrm{DABLI}$, respectively.

The next effective treatment in order of efficacy was $\mathrm{T}_{2}$ [Indoxacarb14.5\% SC @ 0.48 $\mathrm{ml} \mathrm{lit}{ }^{-1}+$ Carbendazim Carbendazim 50 WP @ $3 \mathrm{gm}$ sprayer $^{-1}$ ] showed that 2.03 insect / 15 $\mathrm{cm}$ lac stick on 30 DABLI and 1.81 insect / 15 $\mathrm{cm}$ lac stick recorded after 60 DABLI as compare to farmers practices $\mathrm{T}_{3}$ [Control (Lac growers practice i.e. no use of insecticide)] showed maximum predatory insects $/ 15 \mathrm{~cm}$ lac stick 4.67 on 30 DABLI and 8.33 on 60 DABLI during the year 2015-16 to 2016-17.

The population of predatory insects was varied from 1.5 to 8.33 insect $/ 15 \mathrm{~cm}$ of lac stick. Regarding per cent reduction of the population of $E$. amabilis and $P$. pulverea in different treatments, it varied from 77.78 to 81.97 per cent over control. Among the treatment, $\mathrm{T}_{1}$ [Emamectin benzoatate 5\% SG @ $0.5 \mathrm{ml} \mathrm{lit}^{-1}$ + Carbendazim 50 WP @ 3 gm sprayer $^{-1}$ ] was the best treatment with maximum reduction 81.97 per cent during both the year (Table 2). The present study evidenced by Jaiswal et al., (2017) and Meshram et al., (2018) evaluated the safety of Emamectin benzoate against lac insect $K$. lacca Kerr and bioefficacy against associated lepidopteron predators in lac culture.

\section{Economic analysis}

Economic performance of new molecules against lac predatory insects depicted in (Table 2). The results revealed that the higher average yield $2.15 \mathrm{q}^{-3}$ trees and avoidable loss 49.30 per cent and average net return 17525 Rs. per three (03) in treated trees $\mathrm{T}_{1}$ [Emamectin benzoatate $5 \%$ SG @ $0.5 \mathrm{ml} \mathrm{lit}^{-1}$ + Carbendazim 50 WP @ 3 gm sprayer $\left.{ }^{-1}\right]$ and $2.01 \mathrm{q} / 3$ trees average yield with 15570 Rs. per three (3) trees average net return in treated trees $\mathrm{T}_{2}$ [ Indoxacarb14.5\% SC @ $0.48 \mathrm{ml} \mathrm{lit}^{-1}$ + Carbendazim Carbendazim 50 WP @ 3 gm sprayer ${ }^{-1}$ ] as compare to $1.73 \mathrm{q}^{-3}$ trees average yield and 13000 Rs. per three (3) trees average net return in farmer's practice. The highest cost benefit ratio (B: C) was obtained in $\mathrm{T}_{1}$ [Emamectin benzoatate $5 \%$ SG @ $0.5 \mathrm{ml} \mathrm{lit}^{-1}$ + Carbendazim 50 WP @ 3 gm sprayer ${ }^{-1}$ ] (1:3.43) and (1:3.06) $\mathrm{T}_{2}$ [Indoxacarb14.5\% $\mathrm{SC} @ 0.48 \mathrm{ml} \mathrm{lit}^{-1}+$ Carbendazim Carbendazim 50 WP@3 gm sprayer ${ }^{-1}$ ] in treated trees. Application of these insecticides not only provides ensured lac production but also yielded quality brood lac with no or less predatory insect infestation and present result agreed with the result of Singh et al., (2014).

After application of effective molecules, the increase in the weight of brood lac as well as scraped lac may be due to less infestation by the predators and parasitoids.

\section{Surveillance of lac associated insect fauna}

Lac associated insect fauna (Predators/ parasitoid) in various lac growing areas of Chhattisgarh were collected from kusum host plants of kusumi rainy season crops from different parts of Chhattisgarh are presented on the basis of pooled data during both the year (Table 3 ). 
Table.1 Effect of new insecticide molecules against lac major predatory insects in kusmi lac

\begin{tabular}{|c|c|c|c|c|c|c|c|c|c|c|c|c|c|}
\hline \multirow{4}{*}{$\begin{array}{l}\text { S. } \\
\text { No. }\end{array}$} & \multirow[t]{4}{*}{ Treatments } & \multicolumn{6}{|c|}{ First Spray } & \multicolumn{6}{|c|}{ Second Spray } \\
\hline & & \multicolumn{6}{|c|}{ Number of predatory insect/15 cm lac stick } & \multicolumn{6}{|c|}{ Number of predatory insect/15 cm lac stick } \\
\hline & & \multicolumn{2}{|c|}{30 DABLI } & \multirow[t]{2}{*}{$\begin{array}{c}\text { Pool } \\
\text { ed }\end{array}$} & \multicolumn{2}{|c|}{$\begin{array}{l}\% \text { Reduction } \\
\text { of Predators }\end{array}$} & \multirow[t]{2}{*}{$\begin{array}{c}\text { poole } \\
\text { d }\end{array}$} & \multicolumn{2}{|c|}{60 DABLI } & \multirow[t]{2}{*}{$\begin{array}{c}\text { pool } \\
\text { ed }\end{array}$} & \multicolumn{2}{|c|}{$\begin{array}{c}\% \text { Reduction of } \\
\text { Predators }\end{array}$} & \multirow[t]{2}{*}{$\begin{array}{c}\text { poole } \\
\mathrm{d}\end{array}$} \\
\hline & & $\begin{array}{c}2015- \\
16\end{array}$ & $\begin{array}{c}2016- \\
17\end{array}$ & & $\begin{array}{c}2015- \\
16\end{array}$ & $\begin{array}{c}2016- \\
17\end{array}$ & & $\begin{array}{c}2015- \\
16\end{array}$ & $\begin{array}{c}2016- \\
17\end{array}$ & & $\begin{array}{c}2015- \\
16\end{array}$ & $\begin{array}{c}2016- \\
17\end{array}$ & \\
\hline T1 & $\begin{array}{l}\text { Emamectin } \\
\text { benzoatate 5\%SG@ } \\
0.5 \mathrm{ml} / \mathrm{lit} \\
+ \text { Carbendazim } \\
50 \mathrm{WP} \\
@ 3 \mathrm{gm} / \mathrm{spreyer}\end{array}$ & 1.94 & 1.87 & 1.90 & 53.81 & 63.55 & 58.68 & 1.36 & 1.64 & 1.5 & 83.81 & 80.12 & 81.97 \\
\hline T2 & $\begin{array}{l}\text { Indoxacarb14.5\% } \\
\text { SC@0.48ml/lit+Car } \\
\text { bendazim } \\
\text { Carbendazim 50WP } \\
@ 3 \mathrm{gm} / \mathrm{spreyer}\end{array}$ & 2.1 & 1.96 & 2.03 & 50.00 & 61.79 & 55.89 & 1.89 & 1.73 & 1.81 & 77.5 & 78.06 & 77.78 \\
\hline T3 & $\begin{array}{l}\text { Control (Lac } \\
\text { growers practice i.e. } \\
\text { no use of } \\
\text { insecticide }\end{array}$ & 4.2 & 5.13 & 4.67 & & & & 8.4 & 8.25 & 8.33 & & & \\
\hline & Average & 2.75 & 2.97 & 2.87 & 51.91 & 62.67 & 57.29 & 3.88 & 3.87 & 3.88 & 88.66 & 79.09 & 79.88 \\
\hline
\end{tabular}

DABLI $=$ Days after brood lac inoculation

Table.2 Effect of new insecticide molecules against lac major predatory insects on economics of kusmi lac

\begin{tabular}{|c|c|c|c|c|c|c|c|}
\hline $\begin{array}{l}\text { S. } \\
\text { No. }\end{array}$ & Treatments & $\begin{array}{l}\text { Average Yield } \\
\text { (q./3 trees) }\end{array}$ & $\begin{array}{l}(\%) \\
\text { Avoidable } \\
\text { loss }\end{array}$ & $\begin{array}{l}\text { Average Cost of } \\
\text { cultivation } \\
\text { (Rs./3 trees) }\end{array}$ & $\begin{array}{l}\text { Average Gross } \\
\text { Return (Rs./3 } \\
\text { trees) }\end{array}$ & $\begin{array}{l}\text { Average Net } \\
\text { Return } \\
\text { (Rs./3 trees) }\end{array}$ & $\begin{array}{l}\text { Benefit- } \\
\text { Cost } \\
\text { Ratio }\end{array}$ \\
\hline $\mathbf{T}_{1}$ & $\begin{array}{l}\text { Emamectin benzoatate } \\
5 \% \text { SG@ 0.5ml/lit } \\
\text { +Carbendazim 50WP } \\
\text { @3gm/spreyer }\end{array}$ & 2.15 & 49.30 & 7200 & 24725 & 17525 & $1: 3.43$ \\
\hline$\overline{T_{2}}$ & $\begin{array}{l}\text { Indoxacarb14.5\% } \\
\text { SC@0.48m1/lit+Carbe } \\
\text { ndazim Carbendazim } \\
\text { 50WP @3gm/spreyer }\end{array}$ & 2.01 & 45.77 & 7545 & 23115 & 15570 & $1: 3.06$ \\
\hline$\overline{T_{3}}$ & $\begin{array}{l}\text { Control (Lac growers } \\
\text { practice i.e. no use of } \\
\text { insecticide }\end{array}$ & 1.73 & & 6895 & 19895 & 13000 & $1: 2.89$ \\
\hline & A verage & 1.75 & 47.54 & 7213 & 22578 & 15365 & 1: 3.13 \\
\hline
\end{tabular}

Note: MSP of lac@Rs.100.00/kg in 2015-16, Rs.130.00/kg in 2016-17. 
Table.3 Lac associated insect fauna in Chhattisgarh

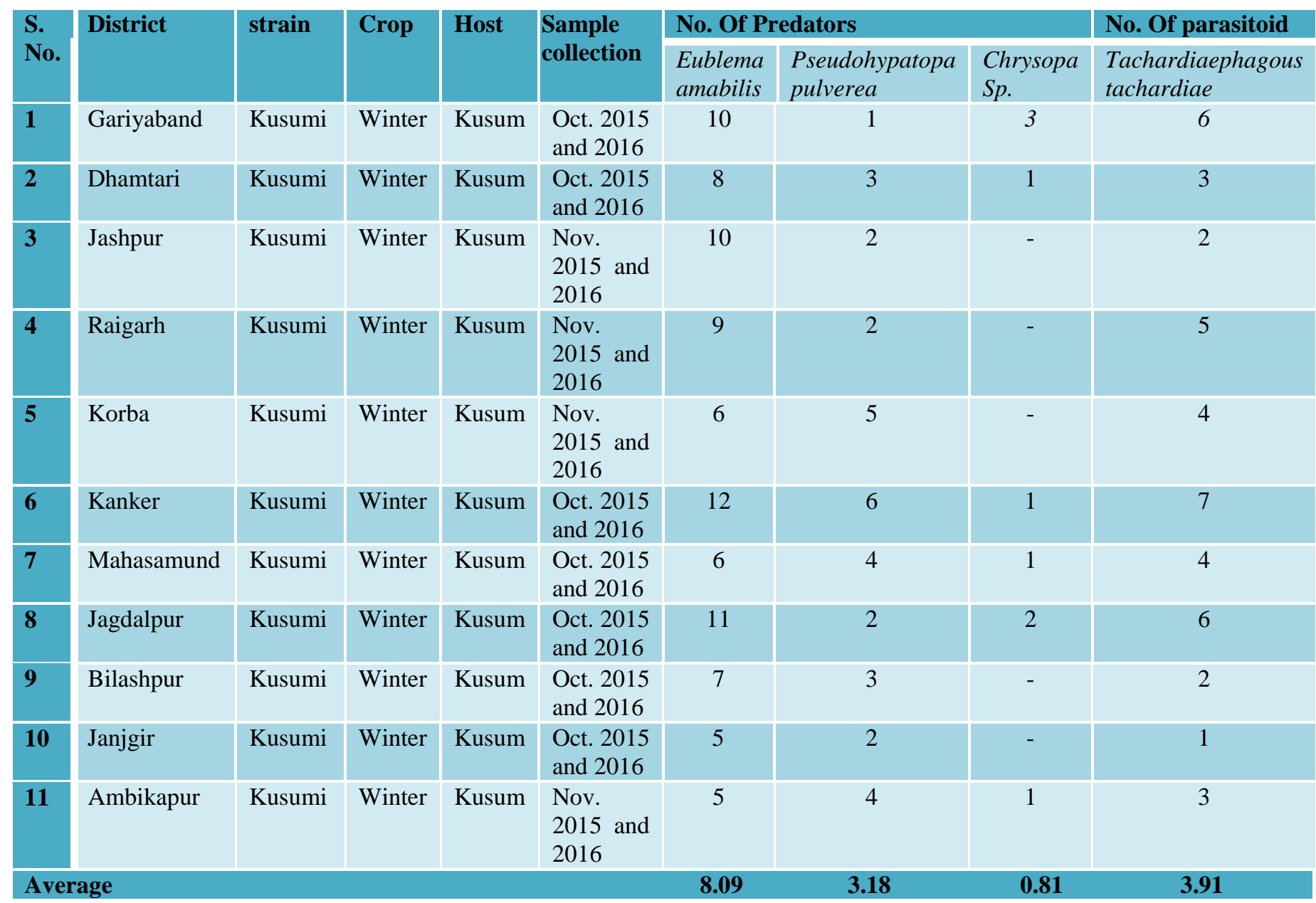

Among the predators Eublema amabilis was recorded as key predator from different lac growing area of Chhattisgarh viz. Kanker, Jagadalpur, Gariyaband, Jashpur, Raigah and Dhamtari with number of larvae/pupa/adult of $12,11,10,9$ and 8 in $15 \mathrm{~cm}$ collected twinges whereas, Pseudohypatopa pulverea was also recorded as major predators at Kanker (6) followed by Korba (5) and Mahasamund (4) whereas Chrysopa Sp. Recorded as minor predator in samples collected from field of Gariyaband (3) followed by Jagadalpur (2). Among the parasitoides of lac insect Tachardiaephagous tachardiae exhibited as major parasitoid with highest number of 7 in Kanker district fallowed by 6,5 and 4 numbers of larvae/pupa/adult in collected samples from Gariyaband, Jagdalpur, Raigarh and Manasamund. The abundance of lac associated fauna differs from crop to crop, place to place and during different month Jaiswal et al., 2001 and Daharia et al., 2013).

The present study revealed that efficacy of new insecticide molecules against lac major predatory insects on the basis of above findings it can be concluded that treatment $\mathrm{T}_{1}$ [Emamectin benzoatate $5 \% \mathrm{SG} @ 0.5 \mathrm{ml} \mathrm{lit}^{-1}$ + Carbendazim 50 WP @ 3 gm sprayer $^{-1}$ ] was the best treatment with maximum reduction 81.97 per cent during the investigation. From the economical point of view, the $\mathrm{T}_{1}$ [Emamectin benzoatate $5 \%$ SG @ $0.5 \mathrm{ml} \mathrm{lit}^{-1}$ + Carbendazim 50 WP @ 3 gm sprayer ${ }^{-1}$ ] 
treatment gave higher net return (17525.00 Rs. per three trees) and benefit: cost ratio $(1: 3.43)$ over rest of the treatments. The judicious use of recommended new insectice molecules, not only provides ensured lac production but also yielded quality brood lac with no or less predatory insect infestation.

\section{Acknowledgement / Funding}

The authors acknowledges the Krishi Vigyan Kendra, Raigarh-496001 Chhattisgarh for providing necessary financial support and other technical inputs during the course of investigation. Authors are also thankful to ICAR-ATARI, Jabalpur (M.P.) for financial assistant provided by conducting the study.

\section{References}

Arora, S., P. Dureja, A.K. Kanoijia and O.M. Bambawale (2009). Pesticide Their Classification Based on WHO and Global Status of Hazardous Pesticides pp110. National Centre for. IPM, LBS Building, Pusa Campus, IARI, New Delhi.

Bhattacharya, A., A.K. Jaiswal and J.P. Singh (2008). Management of lac insect predators through IPM based bioregional approaches. Emerging trends of researches in insect pest management and environmental safety. 1(2): 221-226.

Bhattacharya, A., A.K. Jaiswal, S. Kumar and K.K. Kumar (2006). Management of lepidopteran insect predators of lac insect through habitat manipulation. Entomon Trivandrum, India: Association for Advancement of Entomology. 31(1): 53-56.

Daharia, S.K. and Katlam B.P. (2013). Survy of lac (Kerria lacca Kerr.) natural enemies (predator/ parasitoides) of Chhattisgarh. International Journal of
Recent Scientific Research, 12(4): 1999-2000.

Horn, P. A. and J. Page (2008). Integrated Pest Management for crops and pastures. CSIRO Landlinks Press, Autralia.119p.

Jaiswal, A.K., A. Bhattacharya, S. Kumar and J.P. Singh (2008). Evaluation of Baccillus thuringiensis Berliner subsp. kurstaki for management of lepidopteran pests of lac insect, Entomon. 33: pp. 1-5.

Jaiswal, A.K., A. Bhattacharya, Sunil, S.N. and Kumar, P. (2001). Incidence of lac associated insect fauna in lac growing areas of Jharkhand, India. Journal of Applied Entomology. 15(1): 55-59.

Jaiswal, A.K., K.K. Sharma and K.K. Kumar (2006). Importance of Lac in the socioeconomic life of tribals in Ranchi District (Jharkhand). J. Non-Timb Forest Prod., 13(1): 47-50.

Jaiswal. A.K., Singh, J.P. and Patamajhi, P. 2017. Emamectin benzoate Anovel second generation avermectin derivatives for management of biotic stress in lac culture through treatment of broodlac. Indian Journal of Agricultural Sciences, 87 (9): 1190-1195.

Meshram, Y.K., Bhagat, P.K. and Payal Devi (2018). Management of Prevalence of Natural Enemy, E. amabilis (Moore) by Novel Insecticides at Korba District of Chhattisgarh, India. International Journal of Current Microbial Applied Sciences., special issue (7): 732-737.

Mohanta, J., Dey, D.G. and Mohanty, N. 2012. Performance of lac insect, Kerrialacca Kerr in conventional and non-conventional cultivation around Similipal Biosphare Reserve, Odisa, India, Bioscan, 7: 237-240.

Pal, G. 2009. Impact of scientific lac cultivation training on lac economy: A study in Jharkhand. Agric. Econ. Res. Rev., 22: 139-143. 
Pal, G., A. K. Jaiswal and A. Bhattacharya (2010). Estimation of lac production and processing in India. Environment and Ecology. 28: (1B): 572-576.

Ramani, R. and K. K. Sharma (2010). Record of natural infestation of the Indian lac insect, Kerria lacca (Kerr) (Coccoidea: Tachardiidae) on Acacia tortilis (Forsskal) Hayne and Calliandra surinamensis Benth. Indian Journal of Forestry. 33(2): 189-191.

SiMing, W., C. You Qing, Li Qiao, Lu ZhiXing, Liu ChunJu and Guo ZuXue (2010). The influence of ant-visiting Kerria yunnanensis on populations of
Holcocera pulverea in lac plantation. Chinese Bull. Ento., 47(4): 730-735.

Singh, J.P., Jaiswal, A.K. and Monobrullah, M. (2014). Impact of some selected insecticides an bio-pesticides on incidence of predators, parasitoid and productivity on lac insect, Keerria lacca. Indian Journal of Agricultural Sciences, 84(1): 64-72.

Singh, J.P., Jaiswal, A.K., Monobrullah, M. and A. Bhattacharya (2009). Response of some selected insecticides on neuropteran predator (Chrysopa lacciperda) of lac insect (Kerria lacca). Indian J. Agri.Sci., 79(9): 727-731.

\section{How to cite this article:}

Savita Aditya and Singh, S.P. 2018. Efficacy of New Insecticide Molecules against Major Predatory Insects in Kusmi Lac. Int.J.Curr.Microbiol.App.Sci. 7(12): 100-106.

doi: https://doi.org/10.20546/ijcmas.2018.712.013 